\title{
A Web-Based Learning System for Software Test Professionals
}

\author{
Minhong Wang, Haiyang Jia, Vijayan Sugumaran, Weijia Ran, and Jian Liao
}

\begin{abstract}
Fierce competition, globalization, and technology innovation have forced software companies to search for new ways to improve competitive advantage. Web-based learning is increasingly being used by software companies as an emergent approach for enhancing the skills of knowledge workers. However, the current practice of Web-based learning is perceived as being less goaleffective due to a lack of alignment of learning with work performance. To solve this problem, a performance-oriented approach is presented in this study. Using this approach, a Web-based learning system has been developed for software testing professionals. An empirical study was conducted by inviting employees working in the software testing sector to use and evaluate the system. The results showed the effectiveness of the proposed approach.
\end{abstract}

Index Terms-Education technology, learning system, software testing, training.

\section{INTRODUCTION}

$\mathbf{T}$ RAINING and development of employees are essential for organizational operation and advancement. A lack of software professionals is one of the biggest barriers to the growth of IT and software companies. It may lead to project delays and an increase in employee attrition [1]. In the software industry, knowledge renewal accelerates technological innovations at an incredible pace. Knowledge quickly becomes obsolete as a result of the shortened product lifespans. While companies struggle to keep employees knowledgeable about new technologies in increasingly complex and competitive marketplaces, training departments have to keep up to date with the rapidly changing environment. In this context, how to conduct learning and training programs in an effective way has become one of the most significant issues for software companies.

According to the IEEE [2], "software engineering means application of a systematic, disciplined, and quantifiable approach to development, operation, and maintenance of software." Software engineering education not only concerns software design

Manuscript received February 01, 2010; revised April 17, 2010; accepted May 15, 2010. Date of publication June 17, 2010; date of current version May 04,2011 . This work was supported by a UGC GRF Grant (No. 717708) from the Hong Kong SAR Government and two Seeding Funds for Basic Research (No. 200911159142 and No. 200711159052) from the University of Hong Kong.

M. Wang and W. Ran are with the University of Hong Kong, Hong Kong (e-mail: magwang@hku.hk).

H. Jia is with Jilin University, Changchun 130012, China

V. Sugumaran is with Oakland University, Rochester, MI 48309 USA.

J. Liao is with South West University, Chongqing 400715, China.

Color versions of one or more of the figures in this paper are available online at http://ieeexplore.ieee.org.

Digital Object Identifier 10.1109/TE.2010.2051546 methods and programming languages, but also involves elements such as requirements engineering, software testing, and software quality. In this context, software testing-evaluating the quality of software products by identifying their defects and problems - is an important and mandatory part of software development.

While there is an increased demand for software testing skills in the software industry, there is a dearth of professionals in this field [3]. Universities and schools provide very few courses relevant to software testing, as this subject requires more professional experience. As a result, on-site training programs have become the main channel to acquire the skills of software testing. However, traditional on-site training models often draw on limited resources that are insufficient to support current training efforts. Widely distributed employees need to learn according to their own schedules; traditional on-site training programs face time and space constraints in developing employees' knowledge and skills. Also, the cost of traditional on-site training is too high, especially for small and medium-sized companies. To deal with the problem, IT companies have started to adopt Web-based training or learning facilities as an important supplement to traditional training models. Web-based learning or training provides a variety of opportunities and benefits including: 1) providing just-in-time learning, convenient access, and flexible learning processes; 2) enabling real-time updating of learning content; and 3) facilitating the interconnectivity of people separated by times zones and organizational walls [4], [5].

Although training in IT and software companies has expanded and developed substantially in recent years, Web-based learning is still at the exploration stage. Most Web-based learning applications have performed poorly at motivating employees in active learning. They are perceived as being less goal-effective due to a lack of alignment of learning with work performance [6]-[8]. More often, employees do not think that Web-based learning is helpful since the knowledge learned does not necessarily help improve their work performance. To solve this problem, a performance-oriented approach is presented in this study. This approach uses performance measurement to clarify organizational goals and individual learning needs and links them in Web-based learning applications. The mechanisms needed to operationalize the approach are explored and elaborated upon with conceptual frameworks and implementation details. To demonstrate the effectiveness of the approach, a Web-based learning system for the Testing Unit of a software company has been developed, with relevant experiments to evaluate the effectiveness of the approach. 


\section{PERformance TheORY AND APPROACH}

The concept of performance has a close relationship with "outcome," which attempts to close the gaps between desired and actual educational or training programs. The performance theory pays great attention to learning target and outcomes. It provides an important basis for modeling educational systems, defining and measuring educational outcomes, and improving educational performance. The goal of professional training in the workplace is not merely to teach, but to improve the performance of workers [9]. Performance-based approaches can be applied to: 1) ensure training activities that are driven by business requirements and resulting in targeted performance; 2) support learners and training managers with consistent and accurate administration; and 3) facilitate summative and formative evaluation of training programs for continuous improvement [7], [8].

In this study, a key performance indicator (KPI)-based approach is proposed for the design of a Web-based learning system for software testing professionals. Performance measurement has been used by organizations as a procedure to improve performance by setting performance targets, assessing performance, collecting and analyzing performance data, and using performance results to drive further development. KPIs are financial and nonfinancial metrics used to help organizations define and measure performance progress toward organizational goals [10]. They can bridge the gap between an organization's mission and its employees' targets, making organizational goals achievable. In e-learning, KPIs can be used to help employees set up rational learning objectives according to the performance gap. This approach can be used as a systemic scheme to facilitate training or learning activities in line with work context and performance requirements.

A KPI framework can be designed based on an organization's structure and job system [11]. It consists of three levels: organizational level, business unit level, and position level. KPIs at the organizational level are defined according to business goals and strategies of the organization. Based on the organizational KPIs, the KPIs at the unit level for each business unit can be derived. Based on the unit KPIs, the KPIs at the position level for each job position within the unit are defined. In this study, the focus is placed on KPIs at the position level, which refer to a closer relationship with training development in the workplace.

\section{Conceptual Design}

Based on the performance-oriented approach, a KPI-oriented Web-based learning system was developed for the Testing Unit of PEANUT, a selected medium-sized software company in Mainland China. In this study, a KPI framework is used to identify the KPI items of software testing positions in the software company. KPI is used as an index to direct learning targets and activities and organize and manage learning resources in line with the work context. The design of the KPI framework together with the implementation of the KPI-oriented learning environment using ontology is elaborated as follows.

\section{A. KPI Framework}

To provide fundamental understanding of KPIs, the KPI framework is outlined. It consists of four components: Position,
KPI item, Rating criterion, and KPI value. A KPI item is a performance indicator specified for a job position. For example, "Bug Found Rate" and "Bug Report Rework Rate" can be defined as two KPI items for the junior software tester position. For each KPI item, a rating criterion is set up to assess the performance of that KPI item. For each KPI item, the proficiency level achieved by an employee is called a KPI value. An employee's performance is measured as a set of KPI values of his/her job position. For impartiality and objectivity reasons, most organizations use $360^{\circ}$ feedback to assess employees' performance. An employee's performance can be assessed by performance records from daily work as well as by peer evaluation from the employee him/herself, his/her supervisor, and his/her subordinates or peers. Each appraisal is given a certain weight. As a result, a set of KPI values will be calculated to evaluate the employee's work performance.

The KPI framework in this study is designed according to the company's organizational structure, job system, and performance indicators. The design has also been based on intensive collaboration with the training managers and experts of software testing of the company. Moreover, IEEE standards for software testing [12] have been used and incorporated in the design. A brief illustration of the KPI framework (at the position level) is shown in Table I.

\section{B. KPI-Based Learning Ontology}

To build the KPI-oriented learning environment, ontology is used to specify the KPI framework into a machine-readable format. Ontology is a formal representation of a set of concepts within a domain and the relationships between those concepts. It defines the basic terms and relations comprising the vocabulary of a topic area as well as the rules for combining terms and relations to define extensions to the vocabulary [13]. In e-learning, ontology provides mechanisms for semantic annotation of learning resources and activities, reuse and combining of course materials, and enabling better searching and navigation [14], [15]. Moreover, e-learning materials annotated with semantic tags enable a learning system to reason about learning content and organize it into a customized syllabus according to individual learning needs. In brief, ontology can be used to design the semantic infrastructures of learning objects, model personalized learning environments, and facilitate search and navigation in the learning environment via reasoning in multiple contexts [16].

The main concepts in the proposed KPI-oriented e-learning system include Position, KPI Item, Capability, and Knowledge Component (KC). The KPI learning ontology is constructed based on the four concepts with their relations [17]. As outlined in Table II, an employee at a Position is assessed by a set of KPI Items required by the organization. To improve the performance relevant to a specific KPI Item, the employee needs to develop relevant Capabilities. To develop a Capability, the employee needs to learn relevant knowledge, which can be represented as a number of Knowledge Components (KCs). In addition, relationships between different $\mathrm{KCs}$ and positions are also outlined. For example, one $\mathrm{KC}$ can be linked to another $\mathrm{KC}$ based on relations as prerequisite, composition, and inhibition; a position can be a prior of another position. 
TABLE I

ILLUSTRATION OF THE KPI FRAMEWORK

\begin{tabular}{|c|c|c|c|}
\hline Position & KPI Item & Rating Criterion & KPI Value \\
\hline \multirow[t]{4}{*}{$\begin{array}{l}\text { Junior } \\
\text { Tester }\end{array}$} & \multirow[t]{3}{*}{$\begin{array}{l}\text { Bug Found } \\
\text { Rate }\end{array}$} & $\begin{array}{l}\text { Performance Record (Weight: } 1 / 3 \text { ): } \\
\text { the number of bugs found before delivering } \\
\text { divided by the total number of bugs (found } \\
\text { before + returned from the customers) }\end{array}$ & 0.72 \\
\hline & & $\begin{array}{l}\text { Peer Assessment (Weight: } 1 / 3 \text { ): } \\
\text { Supervisor Assessment (Weight: } 1 / 3 \text { ): } \\
\text { Levels and Criterion defined: } \\
\text { Level 1: score }[0,0.25) \text { : Has little } \\
\text { knowledge/skill for debugging } \\
\text { Level 2: score }[0.25,0.5) \text { : Has basic } \\
\text { knowledge/skill for debugging } \\
\text { Level 3: score }[0.5,0.75 \text { ): Use related } \\
\text { knowledge/skill to accomplish tasks } \\
\text { Level 4: score [0.75, } 1.0] \text { : Use related } \\
\text { knowledge/skill to achieve sound effect }\end{array}$ & $\begin{array}{l}\text { Peer assessment: } 0.7 \\
\text { Supervisor } \\
\text { assessment: } 0.75\end{array}$ \\
\hline & & Overall & $\begin{array}{l}0.72 *(1 / 3)+0.7 *(1 / 3 \\
)+0.75 *(1 / 3)=0.72\end{array}$ \\
\hline & $\begin{array}{l}\text { Bug Report } \\
\text { Rework Rate }\end{array}$ & $\ldots$ & $\ldots$ \\
\hline $\begin{array}{l}\text { Senior } \\
\text { Tester }\end{array}$ & $\ldots$ & $\ldots$ & $\ldots$ \\
\hline
\end{tabular}

TABLE II

RELATIONSHIPS IN THE KPI LEARNING ONTOLOGY

\begin{tabular}{ll}
\hline Relationship & Description of Relationship \\
\hline Hind $(a, b)$ & Position $a$ has a KPI Item $b$ for performance assessment \\
\hline Cap $(a, b)$ & $\begin{array}{l}\text { To improve the performance relevant to the KPI Item } a, \\
\text { Capability } b \text { is required }\end{array}$ \\
\hline $\operatorname{Rkc}(a, b)$ & To improve Capability $a, \mathrm{KC} b$ is needed \\
\hline $\operatorname{Par}(a, b)$ & $\mathrm{KC} a$ is a part of KC $b$ \\
\hline Seq $(a, b)$ & KC $a$ is a prerequisite of KC $b$ \\
\hline $\operatorname{Inh}(a, b)$ & If KC $a$ is learned, then KC $b$ is unnecessary to be learned, \\
\hline $\operatorname{Prp}(a, b)$ & and vise versa \\
\hline \hline
\end{tabular}

The other important concepts in the proposed learning system include KPI Value, Quiz/Test, Quiz/Test Result, and Learning Syllabus, which form the profile of each individual. The relationships between these concepts and the KPI learning ontology are outlined in Fig. 1. Each employee is given a set of KPI values for assessment of his/her job performance. To improve the KPI values, each employee may assess his/her knowledge status relevant to his/her position by taking tests or quizzes. Based on the test/quiz results, the system will recommend a personalized learning syllabus for the employee, which consists of a set of KCs with their relations. Moreover, relevant learning instructions have been specified to guide effective navigation across the knowledge components. For example, a KC is suggested to be acquired after its prerequisite is achieved. The instruction rules are bound with the ontology to support the reasoning process.
In this study, the learning ontology designed for software testing positions has been constructed, a part of which is presented in Fig. 2.

As shown in Fig. 2, "Bug Found Rate" and "Bug Report Rework Rate" are specified as the KPI items for the position "Junior Tester." To improve the performance on "Bug Report Rework Rate," the employees need to develop the capability of "Bug Reporting." To develop the "Bug Reporting" capability, the employees may need to learn relevant KCs such as "Test Fundamentals" and "Defect-based Metrics."

\section{KPI-Oriented Learning Process}

Based on the ontology specified above, the goal of performance-oriented learning can be achieved by setting up rational learning objectives, accessing relevant knowledge artifacts, and 


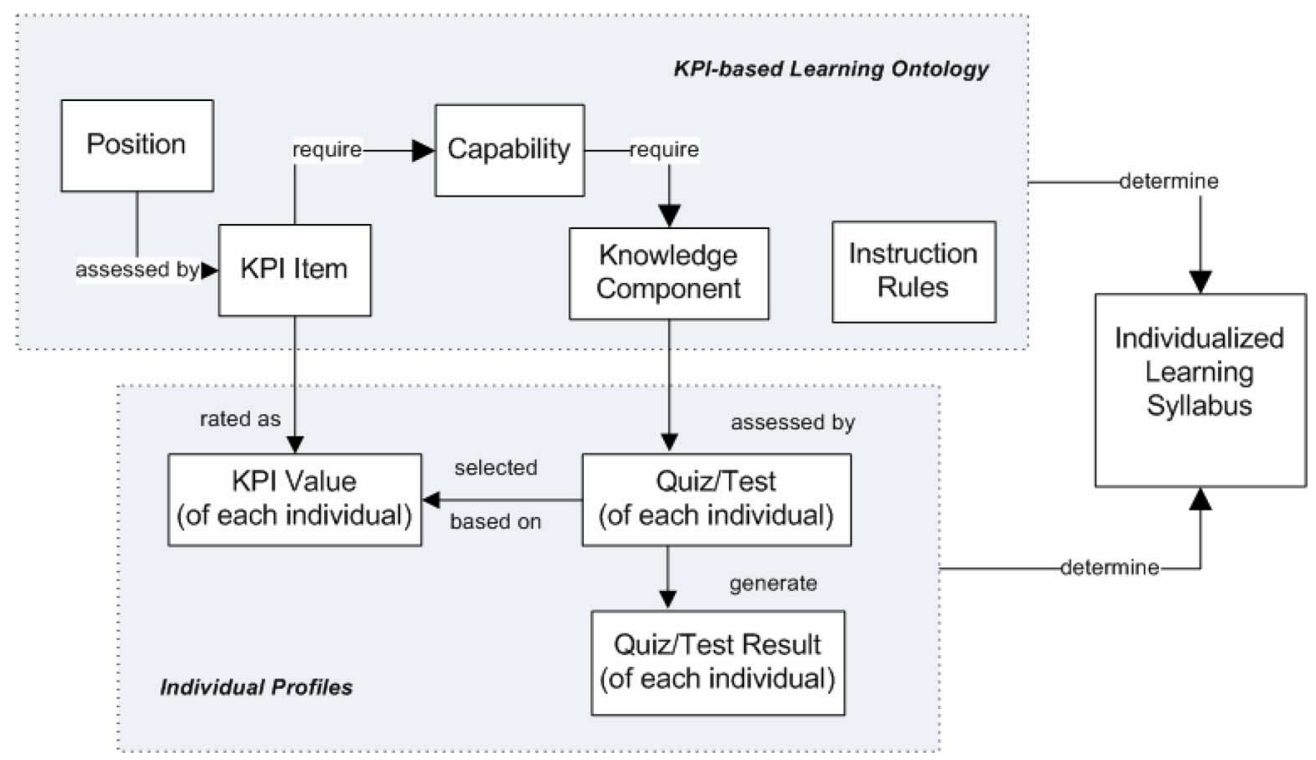

Fig. 1. Concepts and their relationships.

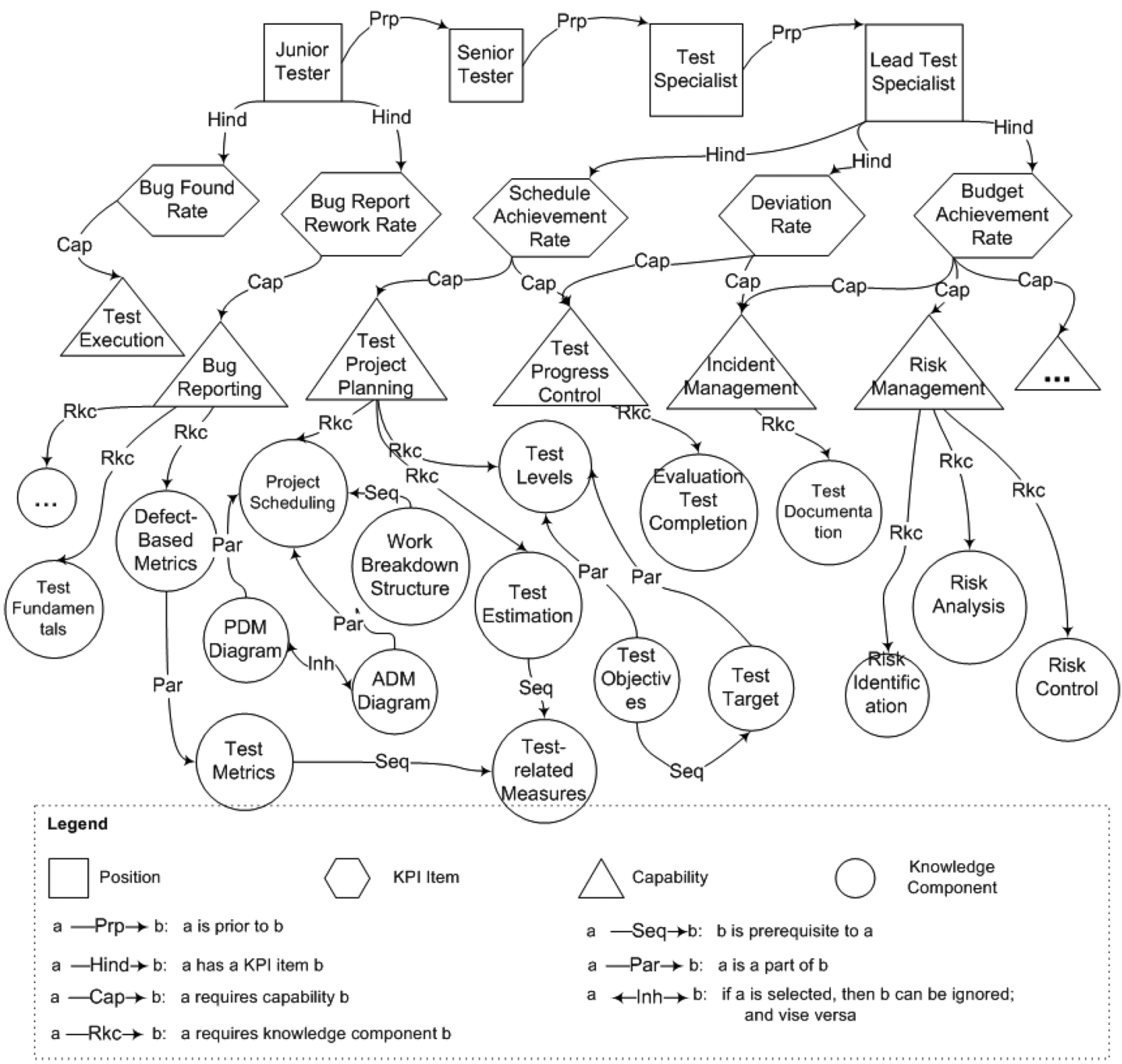

Fig. 2. Learning ontology for software testing. 


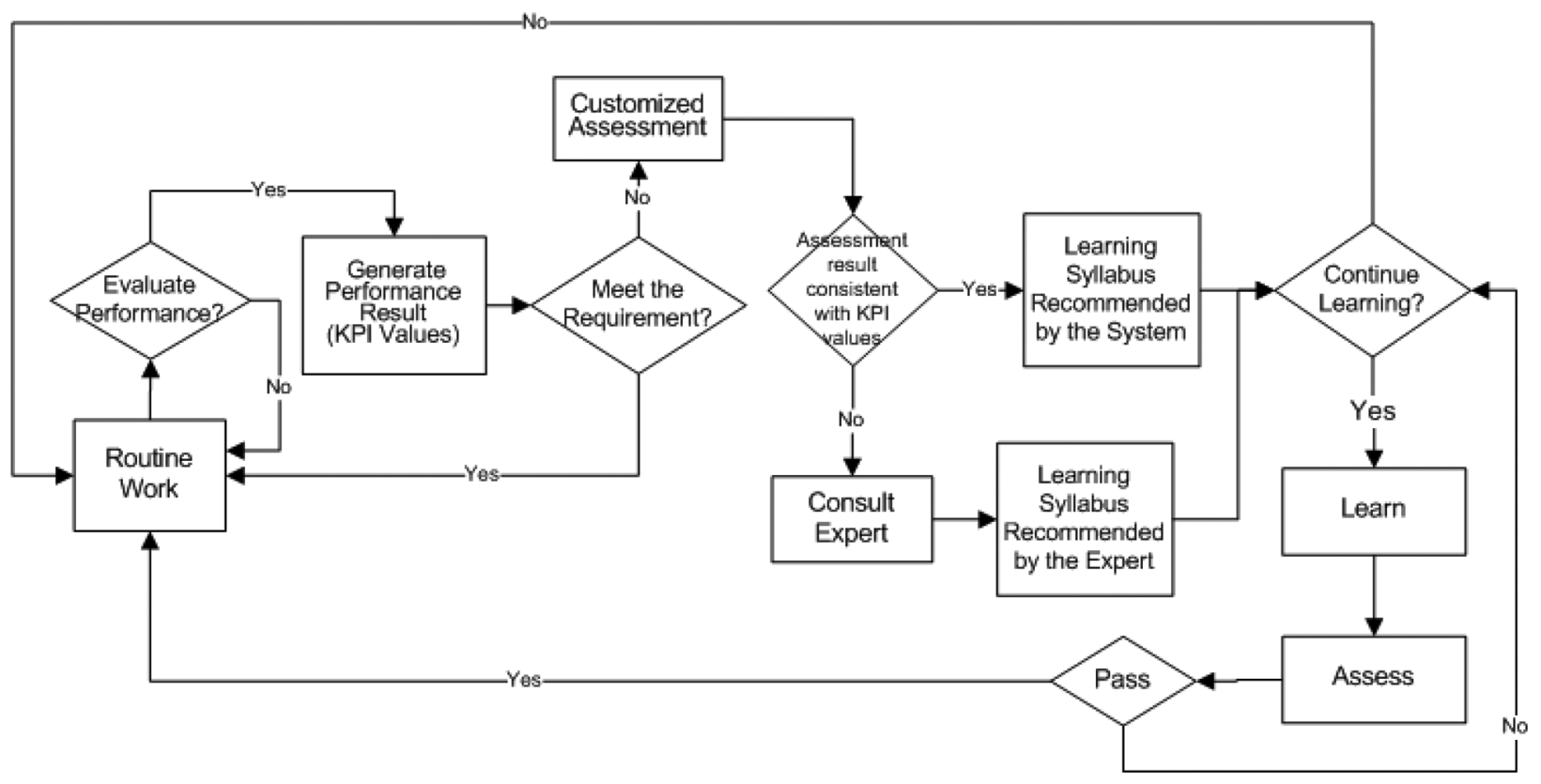

Fig. 3. Learning process.

directing individual learning processes through an appropriate reasoning mechanism. In doing so, the learner's job position should be selected as the target for learning; his/her knowledge gap can be determined based on assessment results. In addition, relevant learning instructions have been specified to allow effective navigation in the learning environment. The details of how the performance-oriented learning process can be facilitated are outlined in Fig. 3, with the detailed reasoning process elaborated in the following.

1) An employee's job performance is evaluated and recorded as a set of KPI values. If one or more KPI values of the employee do not reach the required level, an improvement is suggested.

2) Based on the KPI learning ontology, the system identifies a set of KCs that are relevant for the KPI items to be improved, with the details as follows.

2.1) Based on the relationship between the Position, KPI items, Capabilities, and KCs, a set of KCs that are directly linked to the capabilities under the outstanding KPI items for the employee can be reasoned out, denoted as DKCE.

2.2) In addition to DKCE, the KCs that are indirectly linked to the capabilities under the KPI items (e.g., a prerequisite $\mathrm{KC}$ of another $\mathrm{KC}$ ) are also needed for the employee to learn. All the KCs for an employee $E_{j}$ at a position $P_{i}$ is denoted as $\operatorname{AKCE}\left(P_{i}, E_{j}\right)$. DKCE is a subset of AKCE. With the following rules, AKCE can be reasoned out from DKCE.

$$
\begin{aligned}
& \operatorname{DReq}(a) \rightarrow \operatorname{AReq}(a) \\
& \text { AReq }(a) \wedge \operatorname{Seq}(a, b) \rightarrow A \operatorname{AReq}(b) \\
& \text { AReq }(a) \wedge \operatorname{Par}(b, a) \rightarrow A \operatorname{AReq}(b) \\
& \text { AReq }(a) \wedge \operatorname{Inh}(a, b) \rightarrow A \operatorname{AReq}(b)
\end{aligned}
$$

where $\operatorname{DReq}(a)$ means $\mathrm{KC} a$ is in $\mathrm{DKCE}$, and $A R e q(a)$ means $\mathrm{KC}$ a is in AKCE.

Based on the example shown in Fig. 2, if the employee's performance in "Schedule Achievement Rate" and "Deviation Rate" does not meet the requirement of his/her position, namely, Lead Test Specialist $\left(\mathrm{P}_{3}\right)$, the DKCE for this employee $\mathrm{E}_{1}$ is reasoned out as follows:

$\operatorname{DKCE}\left(\mathrm{P}_{3}, \mathrm{E}_{1}\right)$

$=\{$ Project Scheduling, Test Estimation,

Test Levels, Evaluation Test Completion,

Test Documentation, PDM Diagram,

ADM Diagram, Work Breakdown Structure,

Test Related Measures, Test Metrics,

Test Target, Test Objectives\}.

2.3) If the position $P_{i}$ has one or more prior positions $\left(\mathrm{P}_{0}, \mathrm{P}_{1}, \ldots, \mathrm{P}_{\mathrm{i}-1}\right)$, it is assumed that the employee has already mastered the knowledge for the prior positions before he/she takes the current position $\mathrm{P}_{\mathrm{i}}$. Thus, the necessary $\mathrm{KCs}$ for the employee $\mathrm{E}_{\mathrm{j}}$ at the position $\mathrm{P}_{\mathrm{i}}$, denoted as $\operatorname{KCE}\left(\mathrm{P}_{\mathrm{i}}, \mathrm{E}_{\mathrm{j}}\right)$, can be reasoned out of $\operatorname{AKCE}\left(\mathrm{P}_{\mathrm{i}}, \mathrm{E}_{\mathrm{j}}\right)$ by removing the $\mathrm{KCs}$ of the prior positions as the following:

$$
\operatorname{KCE}\left(P_{i}, E_{j}\right)=\operatorname{AKCE}\left(P_{i}, E_{j}\right)-\sum_{\text {where } m=0,1, \ldots, i-1 .} \operatorname{KCP}\left(P_{m}\right),
$$

3) Based on KCE (the necessary KCs for the employee to learn), a customized assessment package is generated to test the employee's knowledge status. The employee's learning profile will be updated based on the assessment results. Based on the assessment results, the $\mathrm{KCE}$ can be 
further refined into RKCE by removing the KCs that have already been mastered by the employee.

Some reasoning rules will be used for the refinement. For example, if $\mathrm{KC} a$ has an alternate or inhibitor $\mathrm{KC} b$, there is no need to learn $\mathrm{KC} a$ and $\mathrm{KC} b$ at the same time. The rules for refinement are specified as follows:

$$
\begin{aligned}
\operatorname{Req}(a) \wedge & \neg \operatorname{Mas}(a) \wedge \neg \exists b \operatorname{Inh}(a, b) \rightarrow, \operatorname{Req}_{r e f}(a) \\
\operatorname{Req}(a) \wedge & \neg \operatorname{Mas}(a) \wedge \forall b(\operatorname{Inh}(a, b) \wedge \neg \operatorname{Mas}(b) \wedge H s c(a, b)) \\
& \rightarrow \operatorname{Req} q_{r e f}(a)
\end{aligned}
$$

where $\operatorname{Req}(a)$ means $\mathrm{KC} a$ is covered in $\mathrm{KCE}, ; \operatorname{Req}_{r e f}(a)$ means KC $a$ is in RKCE, $\operatorname{Mas}(a)$ means KC $a$ has been mastered by the user, and $\operatorname{Hsc}(a, b)$ means the test score of $\mathrm{KC} a$ is higher than that of $\mathrm{KC} b$.

Following the example in Fig. 2, if the assessment results show that the learner has mastered the KC "Evaluation Test Completion" and the score for "ADM Diagram" is higher than that of "PDM Diagram," then the KC "Evaluation Test Completion" and "PDM Diagram" can be removed from the employee's learning scope.

4) If the assessment results are consistent with the KPI values, the system will generate a personalized learning syllabus (a set of KCs and their relations) to guide the learning process of the employee; otherwise, the employee will be recommended to consult a domain expert.

The syllabus is a strict partial order [18] of KCs in RKCE. The syllabus is determined by the following rules, where $a>b$ means KC $a$ should be learned before $\mathrm{KC} b$ :

$$
\operatorname{Seq}(a, b) \rightarrow b>a ; \quad \operatorname{Par}(a, b) \rightarrow a>b
$$

Based on the example discussed above, the knowledge components included in the learning syllabus are reasoned out as follows:

$\operatorname{RKCE}\left(\mathrm{P}_{3}, \mathrm{E}_{1}\right)$

$=\{$ Test documentation, Test Objectives,

Test Target, Test Levels, ADM Diagram,

Project Scheduling, Work Break down Structure,

Test Metrics, Test - related Measures,

Test Estimation\}.

5) The employee starts to learn according to the learning syllabus recommended by the system or domain expert. During the learning process, quizzes or tests, mainly in single or multiple-choice formats, are provided for the employee to assess their level of understanding of the subject matter.

6) If the employee is not able to pass the quiz or test within a specified time frame, the system will provide additional learning resources or suggestions such as supplemental materials relevant to the $\mathrm{KCs}$, prerequisite knowledge that the learner should have already mastered before he/she was promoted to the current position, and other advice from the domain expert. The employee may continue to learn until he/she quits the learning process.

In addition to the individual learning process, social networking is also facilitated in the learning environment. Learners are able to contribute and evaluate the learning resources, discuss their learning problems or experiences at forums, and conduct peer evaluation of their work performance. Each employee is provided with a KPI identification, i.e., a set of KPI values that indicates his/her expertise and proficiency level, stored in the learner's profile. Based on KPI identifications and contribution to the learning community, learners are able to become familiar with each other to make more effective communication. In this way, self-directed and socially constructed learning activities can be effectively directed via integration of organizational objectives, individual needs, and social context in the workplace [19].

\section{SYSTEM IMPLEMENTATION}

To demonstrate the effectiveness of the approach, a prototype of the KPI-oriented learning system has been developed using Java programming tools. In the prototype, three interfaces are provided for learner, training manager, and domain expert. The interfaces enable different roles of users to access relevant functions of the learning system and communicate with each other. The Learner Interface enables a learner to maintain personal information, access and evaluate learning resources, take tests, share learning materials, participate in discussions, conduct peer assessment, and contact domain experts and training managers for inquires. The Expert Interface enables a domain expert to refine the KPI model, maintain learning materials, communicate with learners, assess learners' performance, and coordinate discussions. The Manager Interface enables a training manager to manage learners' profiles, maintain the assessment base, make announcements, and manage the KPI model with domain experts.

To implement the learning ontology, computational languages and tools have been used in developing the prototype. OWL-DL (Description Language) is used to define the KPI-based learning ontology. To support the reasoning services, instruction rules are bound with the ontology using DL safe SWRL (Semantic Web Rule Language). To implement both OWL ontology and SWRL rules, OWL-API was used to access Pellet [20] as the semantic reasoning tool. Moreover, to enable domain experts and training managers to construct and maintain the ontology, tools for ontology editing and visualization are necessary. In this study, Protégé, a free open-source ontology editor [21], together with other plug-ins are employed.

A set of screenshots from the prototype is presented in Fig. 4. The ontology editing screen (upper left of Fig. 4) shows the interface for editing the ontology, which is discussed in the early example in Fig. 2. Protégé is used to edit the ontology. In addition, "Jambalaya tab," a plug-in for Protégé, is used to visualize the ontology; "SWRL tab," another plug-in for Protégé, is used to edit the rules bounded with the ontology for reasoning purpose. As a result, the KPI learning ontology is visualized as a graph for easy communication of the learning context. By clicking on a $\mathrm{KC}$ in the ontology graph, the user is able to locate the learning objects or assessment package linked to the $\mathrm{KC}$. The personalized learning syllabus screen (lower right of Fig. 4) shows a personalized learning syllabus recommended by the system, which is discussed in the early example in Fig. 2 . The lower left part of Fig. 4 shows the screen for taking a quiz 


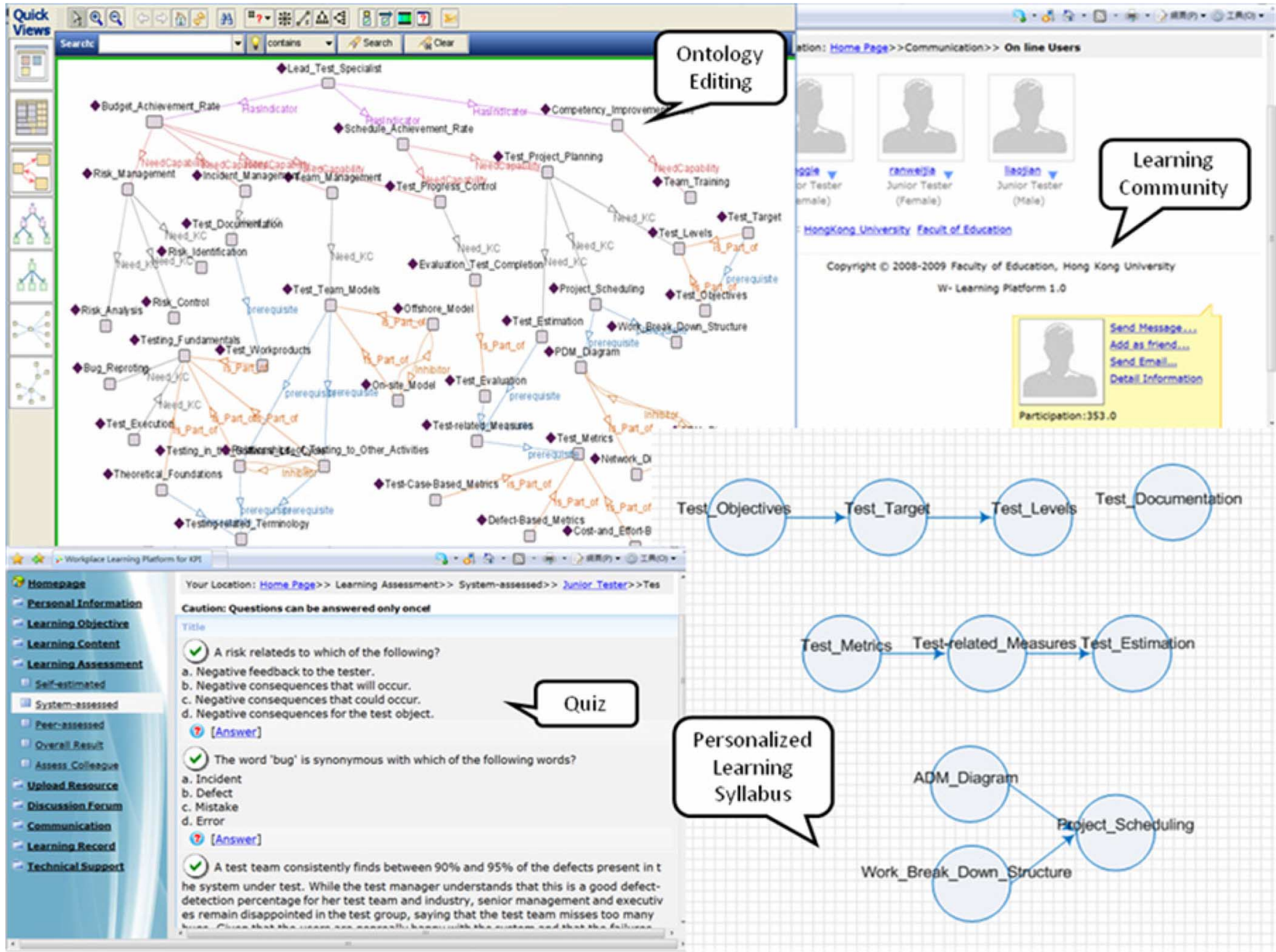

Fig. 4. Screenshots of the prototype.

in order to assess the learner's knowledge relevant to a specific KC. The upper right part of Fig. 4 shows the screen for communication and discussion between learners. During the communication, learners are able to select peer learners or experts according to their profiles, which record their background, expertise, and contribution to the learning community.

\section{EVALUATION}

This section describes the empirical evaluation of the developed system to demonstrate its effectiveness. Twenty-four employees who were currently working or had previously worked with the Testing Unit of the company participated in the experiments. Two parallel prototypes were used for evaluation: the developed KPI-oriented system (System A) and another traditional system without KPI support (System B). System B has similar functions to System A in terms of user management, learning resources, assessment management, and communication tools, but without KPI-oriented facilities. The participants were divided into two groups of 12: the treatment group that used the KPI-based system and the control group that used the traditional system. There was no significant difference between the treatment group and the control group in software industry work experience and the number of e-learning systems used before.

The data collection process can be divided into four stages. First, the participants finished the pretest. Second, after using the system for four weeks, participants completed the post-test and the first questionnaire for evaluation of the workplace e-learning system on Reaction, Learning, Behavior, and Result level. Third, the two groups were asked to swap systems and use the systems for two weeks; at the end of the stage, the second questionnaire was used to determine participants' preference toward the two prototypes. Finally, interviews were conducted for qualitative feedback from the participants, as well as to obtain their opinions of the e-learning system.

The evaluation was conducted based on Kirkpatrick's model [22], which includes four levels: Reaction (how participants react to the learning system); Learning (knowledge learning or skill development by using the application); Behavior (transfer of learning into change of behavior by using the system); and Result (organizational and individual outcome as a result of the training program). Questionnaire items were developed based mainly on Kirkpatrick et al. [22] and Sun et al. [23] with respect to the evaluation of workplace learning and e-learning systems. The evaluation framework is outlined in Table III. 


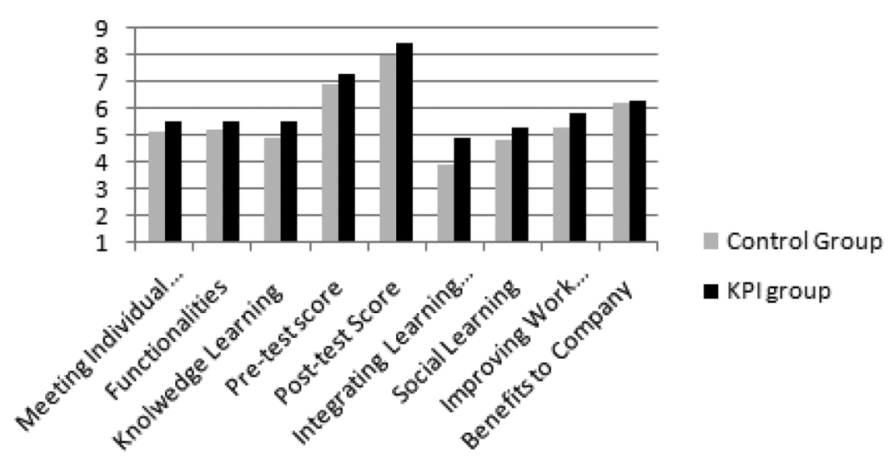

Fig. 5. Evaluation of the learning systems (first-round evaluation).

TABLE III

EVALUATION FRAMEWORK

\begin{tabular}{ll}
\hline \hline Level & Aspect \\
\hline \multirow{2}{*}{ Reaction } & Meeting individual learning requirement \\
\cline { 2 - 2 } Learning & Functionalities for learning \\
\cline { 2 - 2 } Bnowledge learning and skill development & Pre-test score vs. Post-test score \\
\hline \multirow{2}{*}{ Behavior } & Integrating learning with work practice \\
\cline { 2 - 2 } Result & Social learning \\
\cline { 2 - 2 } & Bmproving work performance \\
\hline
\end{tabular}

The participants' evaluation of the system was mainly based on their perceptions measured on a Likert scale (from 1-strongly disagree to 7-strongly agree). Pretest and post-test questions were designed based on certification examinations in the software testing profession and adjusted by the domain experts.

The results obtained from the first questionnaire are shown in Fig. 5. It was found that the KPI-oriented system was perceived to be more effective in terms of meeting individual learning requirement and functional support for learning (Reaction); the KPI-oriented system was perceived to be more helpful to learners in obtaining knowledge and skill (Learning); the KPI-oriented system was perceived to be more helpful in enabling learners to integrate learning into practice and transform individual learning into collaborative learning (Behavior); and the KPI-oriented system was perceived to lead to better outcomes in improving work performance (Result). On the other hand, the results of the pretest and post-test scores indicated that there was no significant difference between the two groups in the pretest or post-test scores. The results are understandable, as other factors associated with the learners (e.g., their learning capability and effort) as well as their learning environment (e.g., Internet accessibility, speed, and cost) may have affected the results. In addition, the benefit of the KPI-oriented system to the company was not perceived as significant in the first-round evaluation. However, it was perceived as significant in the second evaluation and in further interviews with the managers.

As a supplement to the first-round evaluation, the secondround evaluation was conducted by swapping the learning systems between the two groups. Twenty out of 24 participants completed the second-round evaluation. The results of the evaluation-that is, the participants' preference between the two

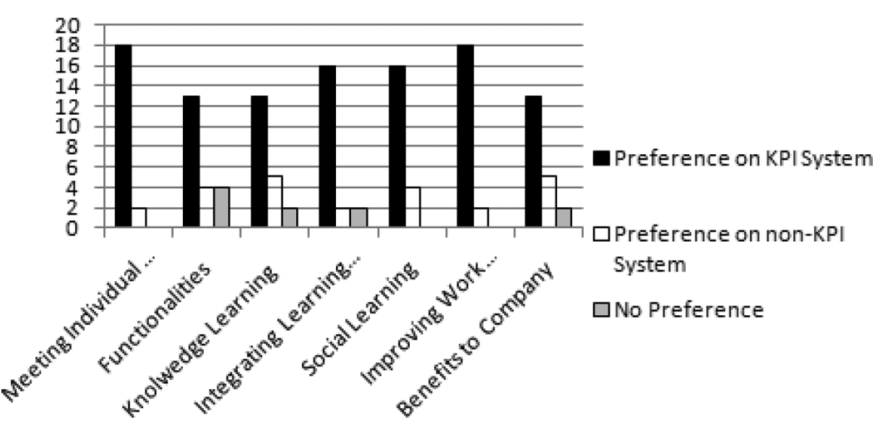

Fig. 6. Preference on the learning systems (second-round evaluation).

learning systems-is shown in Fig. 6. The results show that a majority of the participants preferred the KPI-oriented learning system concerning all the aspects of the system.

The findings from the surveys are positive but limited due to the small sample size and short period of the experiment. Other results from the interviews showed a more positive evaluation of the KPI-oriented system, especially in terms of providing a clear picture of what needs to be learned in order to develop specific skills. The learners also gave positive comments about the KPI-oriented system concerning its facilities for effective communications, knowledge sharing, and discussion. At the same time, they suggested more instructions or technical support be provided before the experiment, which may reduce the time spent on becoming familiar with the system. In addition to the learners, the training managers and domain experts were interviewed. The experts gave more positive comments on the KPI-based learning system than the learners. Moreover, the experts stressed the importance of providing convenient and instant help for learners to solve their learning problems. As for the training managers, their major concern was cost, which may affect the benefits to the organization from using the learning system. The cost refers to setting up the KPI framework and developing the KPI-based learning system. Based on the experience of this study, this may require one month's intensive discussion of the KPI model with managers, experts, and employees and one month's KPI ontology development by a senior programmer, in addition to the cost of developing a traditional Web-based learning system. As a result, the developed e-learning system may not necessarily bring significant benefits to the company in the short term. However, the training managers gave positive comments on the KPI-oriented learning system since they felt that it provided flexible ways of learning and assessment.

\section{CONCLUSION AND DISCUSSION}

In a rapidly changing industrial world, ever more emphasis is placed on thorough and continuous education and training programs in software engineering. At the same time, the use of computer and network technology to deliver learning has become the latest trend in the training and development industry. This study addressed the problem of Web-based learning systems development, i.e., most e-learning systems are perceived as being less goal-effective due to a lack of alignment of learning with work performance. To solve the problem, a performanceoriented approach was presented in this study. The key idea lies 
in a KPI model, where the mission and vision of a company are translated into a set of key performance targets that drive learning toward the goal of improving work performance. KPIs are used for assisting organizations to clarify their training objectives, helping individuals make sense of work context and performance requirement, and accordingly helping individuals set up rational learning objectives, access relevant knowledge resource, and communicate with relevant peers and experts (according to their KPI profiles) to enhance their learning process. To demonstrate the approach, a Web-based learning system was developed for the software testing sector. The system development was customized to the profession of software testing. An empirical study was conducted by inviting a group of employees working in the testing sector to use and evaluate the effectiveness of the system.

The e-learning system presented in this study for software testing profession can also be applied to a training course that sets learners on the path to true testing professionalism. The aim of the course is to deliver basic concepts, essential ideas and processes, and advanced techniques required for professional software testers. The students selected for the course should have prerequisite knowledge including software engineering, software design methods, and programming languages. The content will cover fundamentals of testing, static techniques, test design, test management, test tools, test approaches and strategies, and so on After studying this course, students should be able to define the mission of software testing, examine various testing types and techniques, analyze and report defects effectively, and assess and report the extent of testing. The assessment approaches may include quizzes, tests, or peer assessment, among others. The key pedagogical issue is to link knowledge learning with work performance in software testing.

Other studies related to this may refer to competency-based learning, where learning is driven by development of specific competencies for dealing with needs and challenges [24], [25]. Current work in this field has focused more on learning content and has underestimated the complexity of the interactions or alignment between employees and organizations. Other related work includes e-learning system development with ontology support, which can be found in a number of studies such as [14]-[16]. Compared to other people's work, the ontology and system developed in this study has gone beyond learning content by including learning objectives and assessment in line with the KPI model. In this way, a sound pedagogical underpinning is provided for ontology construction with the aim of facilitating a performance-oriented learning in the workplace.

It should also be noted that this work has focused on learning development in view of short-term needs to improve work performance. In workplace settings, learning needs should be extended to enhance personal and career development in the long term. Ongoing learning is now a necessity for most employees and essential for those engaged in transitions across work and occupational boundaries. Future work should look into long-term needs of workplace learning by integrating economic, social, and personal dimensions and adopting human resource management and organizational learning perspectives.

\section{REFERENCES}

[1] T. Acton and W. Golden, "Training the knowledge worker: A descriptive study of training practices in Irish software companies," J. Eur. Indus. Training, vol. 27, no. 2, pp. 137-146, 2003.

[2] IEEE Standard Glossary of Software Engineering Terminology, ANSI/ IEEE Standard 610.12, IEEE, 1990.

[3] "Career options for software test professionals," Software Testing Help, retrieved Jan. 2008 [Online]. Available: http://www.softwaretestinghelp.com/career-options-for-software-test-professionals/

[4] M. J. Rosenberg, Beyond e-Learning: Approaches and Technologies to Enhance Organizational Knowledge, Learning, and Performance. San Francisco, CA: Pfeiffer, 2006.

[5] O. Z. Ozdemir and J. Abrevaya, "Adoption of technology-mediated distance education: A longitudinal analysis," Inf. Manage., vol. 44, no. 5, pp. 467-479, 2007.

[6] L. Servage, "Strategizing for workplace e-learning: Some critical considerations," J. Workplace Learning, vol. 17, no. 5/6, pp. 304-317, 2005.

[7] M. Wang, W. Ran, J. Liao, and S. J. H. Yang, "A performance-oriented approach to e-learning in the workplace," Educ. Technol. Soc., to be published.

[8] M. Wang, H. Jia, W. Ran, V. Sugumaran, and J. Liao, "Ontology-based intelligent agents in workplace e-learning," in Proc. AMCIS, San Francisco, CA, 2009.

[9] H. D. Stolovitch and E. J. Keeps, "Foreword," in Handbook of Human Performance Technology, J. Pershing, Ed. San Francisco, CA: Pfeiffer, 2006.

[10] D. Parmenter, Key Performance Indicators (KPI): Developing, Implementing, and Using Winning KPIs. Hoboken, NJ: Wiley, 2007.

[11] T. Baker, Key Performance Indicators Manual: A Practical Guide for the Best Practice Development, Implementation and Use of KPIs. South Melbourne, Vic., Australia: Pitman, 1995.

[12] A. Bertolino, "Software testing," in Swebok: Guide to the Software Engineering Body of Knowledge, A. Abran and J. W. Moore, Eds. Piscataway, NJ: IEEE, 2001, ch. 5, Trial Version 1.00.

[13] R. Neches, R. E. Fikes, T. Finin, T. R. Gruber, T. Senator, and W. R. Swartout, "Enabling technology for knowledge sharing," AI Mag., vol. 12, no. 3, pp. 36-56, 1991.

[14] F. Colace and M. D. Santo, "Ontology for E-learning: A Bayesian approach," IEEE Trans. Educ., vol. 53, no. 2, pp. 223-233, 2010.

[15] A. Gladun, J. Rogushina, F. García-Sánchez, R. Martínez-Béjar, and J. T. Fernández-Breis, "An application of intelligent techniques and semantic Web technologies in e-learning environments," Expert Syst. Appl., vol. 36, pp. 1922-1931, 2009.

[16] C. Knight, D. Gašević, and G. Richards, "An ontology-based framework for bridging learning design and learning content," Educ. Technol. Soc., vol. 9, no. 1, pp. 23-37, 2006.

[17] H. Jia, M. Wang, W. Ran, and J. Liao, "Ontology and key performance indicator based workplace e-learning environment," in Proc. 13th GCCCE, Taiwan, 2009.

[18] B. Schröder, Ordered Sets: An Introduction. Cambridge, MA: Birkhäuser, 2002.

[19] M. Wang, "Integrating organizational, social, and individual perspectives in Web 2.0-based workplace e-learning," Inf. Syst. Frontiers, 10.1007/s10796-009-9191-y, to be published.

[20] E. Sirin, B. Parsia, and B. C. Grau, "Pellet: A practical OWL-DL reasoner," Web Semantics, vol. 5, no. 2, pp. 51-53, 2007.

[21] N. F. Noy, R. W. Fergerson, and M. A. Musen, "The knowledge model of Protege-2000: Combining interoperability and flexibility," in Proc. 2nd EKAW, France, 2000, pp. 1-20.

[22] D. L. Kirkpatrick and J. D. Kirkpatrick, Evaluating Training Programs, 3rd ed. San Francisco, CA: Berrett-Koehler, 2006.

[23] P. C. Sun, R. J. Tsai, G. Finger, Y. Y. Chen, and D. Yeh, ““'What drives a successful e-learning?" An empirical investigation of the critical factors influencing learner satisfaction," Comput. Educ., vol. 50, no. 4, pp. 1183-1202, 2008.

[24] T. Ley, A. Ulbrich, P. Scheir, S. N. Lindstaedt, B. Kump, and D. Albert, "Modelling competencies for supporting work-integrated learning in knowledge work," J. Knowl. Manage., vol. 12, no. 6, pp. 31-47, 2008.

[25] A. Schmidt, "Bridging the gap between knowledge management and e-learning with context-aware corporate learning," Lecture Notes Artif. Intell., vol. 3782, pp. 203-213, 2005. 
Minhong Wang received the Ph.D. degree in information systems from the City University of Hong Kong in 2005.

She is an Assistant Professor with the Faculty of Education, The University of Hong Kong. She has published papers in Information and Management, Expert Systems with Applications, Knowledge-Based Systems, and Educational Technology \& Society. Her current research interests include e-learning, Web-based training, knowledge management, business process management, and information systems.

Dr. Wang is the Editor-in-Chief of Knowledge Management \& E-Learning: an International Journal (KM\&EL), and serves on the Editorial Board of several international journals. She has also served as Chair and Program Committee member for a number of conferences.

Haiyang Jia received the Ph.D. degree in computer science from Jilin University, Changchun, China, in 2008.

He is a Senior Research Assistant with the Faculty of Education, The University of Hong Kong. He works in the College of Computer Science and Technology, Jilin University. His research interests include probabilistic graphical models, Bayesian networks, machine learning, data mining, artificial intelligence, and knowledge engineering.
Vijayan Sugumaran received the Ph.D. in information technology from George Mason University, Fairfax, VA, in 1993.

$\mathrm{He}$ is a Professor of Management Information Systems with the Department of Decision and Information Sciences, Oakland University, Rochester, MI. His most recent publications have appeared in Information Systems Research, ACM Transactions on Database Systems, IEEE TRANSACTIONS ON ENGINEERING Management, Communications of the ACM, Healthcare Management Science, Data and Knowledge Engineering, The DATABASE for Advances in Information Systems, and Information Systems Journal. His research interests are in the areas of ontologies and semantic Web, intelligent agent and multiagent systems, component-based software development, knowledge-based systems, and data and information modeling.

$\mathrm{He}$ is the Editor-in-Chief of the International Journal of Intelligent Information Technologies and also serves on the Editorial Board of eight other journals. He has served as Chair and Program Committee member for a number of national and international conferences.

Weijia Ran received the B.Sc. degree in information management and information systems from Nanjing University of Posts and Telecommunications, Nanjing, China, in 2003. She is currently an M.Phil. student with the Faculty of Education, The University of Hong Kong. Her current research interests include workplace learning, information systems, knowledge management, and organizational management.

Jian Liao received the M.Phil. degree in educational technology from Beijing Normal University, Beijing, China, in 2008.

$\mathrm{He}$ is a Research Assistant with the Faculty of Education, The University of Hong Kong. He works in the School of E-Learning, South West Normal University. His current research interests include knowledge management, computer-supported collaborative learning, and e-learning. 